\title{
Developing Curriculum-Led Human-Centred Spatial Design Briefs for Next Generation Learning Environments in Higher Education
}

\author{
Susan Sherringham, University of Technology Sydney, NSW, Australia
}

\begin{abstract}
There have been major shifts in learning goals, curricula and pedagogy over the past century, particularly the last thirty years. In the last decade the area of learning space design has emerged as a key research focus, policy priority and strategic direction in both schools and the higher education sector: In response to these major shifis, imnovative spatial approaches to learning have given rise to 'next generation' learning environments. These environments address a multiplicit and fuid set of parameters and considerations. The rate of change in the sector and in techology, shifts in pedagogy and conceptions of learning, and the needs and expectations of new generations of students all give rise to a far more complex process than the design of raditional learning spaces. In the conception of these next generation learning environments the relationships between the users, curriculum, pedagogy, technology and spatial enviroments are recognized as fluid and evolving and influenced by a diverse array of stakeholders both within and beyond the campus. Intrinsic to these relationships are strategic directives, objectives and transformative processes acting on macro and micro levels. It is this complexity and interelatedness that signals the need for wiversities to not only rethink the typology of environments for learning but also the process for conceiving, briefing and creating them. It is this need, and the paucity of research in this area, that defines the focus of this paper and an Australian Learning and Teaching Council funded research project from which this paper stems. The project is mapping a protocol for the development of curriculum-led human-centred spatial design briefs for next generation learning environments. This paper presents the designerly approach to the research project, the methods for investigation, brief development and the 'tools' being developed and tested.
\end{abstract}

Keywords: Visual Action Research Methods, Curriculum-1.ed, Transformalive Processes, Participatory design and play, Learning linvironments, Photo elicitation

\section{Introduction}

$\mathrm{F}$

UELLED BY EDUCATION reform and government funding, the higher education sector has seen intense activity in research and infrastructure development in the area of learning environments. Emerging from the flurry of activity in this area is the identification of a critical gap in the process. As Jamieson states, there is a strong need for 'universities to rethink not only the types of physical settings that are necessary (for learning), but also the process for creating them' (Jamieson 2007). This gap has arisen out of rapid change in the sector including shifts in pedagogical approaches and conceptions of learning coupled with the ubiquitous growth and use of technology. As a result the design of next generation learning spaces represents a far more complex process due to the number of variables, the rate of change in the sector and in technology, and the rapidly changing needs and expectations of new generations of students.

Design Principles and Practices: An International Jounal

Volume 4, Number 3, 2010, ht1p://Www.Design-Joumalcom, ISSN 1833-1874

0 Conmon Ground, Susan Sherringham, All Rights Reserved, Permissions:

og-support(ocommongromentpublishing.con 
DESIGN PRINCIPLES AND PRACTICES: AN INTERNATIONAL JOURNAL

There is a growing body of research in the area of design for learning spaces and whilst it provides some useful case studies of next generation learning spaces and broad first principles, there is no protocol to guide those involved through the complex process of conceiving, briefing and creating next generation learning environments. This paper presents a research project that is developing such a protocol. In presenting the research project, this paper will provide an overview of the projects aims and objectives, the methodology for the research, and the methods and tools being used and developed through the iterative cycles of the research investigation.

\section{Project Overview}

The research is being conducted in an action research framework, whereby insights gained from cycles of critical reflection and action (by researchers and participants in the fieid) guides the research process. The aim of this ALTC project is to develop a series of protocols, tools and models to assist in the conceptualization, design, implementation and post-occupancy evaluation of next generation learning environments. These protocols involve stakeholder consultation through various forms of engagement including interviews, focus groups, workshops, joumals and surveys. This represents a dynamic soft-systems approach that takes into account the evolving nature and interrelationships of and between space, technology, pedagogy, curriculum and learning as complex open systems or human activity systems (Johnson \& Lamas, 2005; Loi \& Dillon, 2006).

The project brings together a team of experienced academics and design practitioners who are all in some way researching the development of learning environments. Team members are developing an open, inclusive project framework that draws on the experience of staff from three universities. The team members' research backgrounds and experience in both Education and Interior Design contribute to a rich understanding of the process and aims of learning space design. This expertise brings into focus the relationship between space and its occupants; practices [for example leaming and teaching], projects, communications, identities and 'things' (Warde, Borgmann, Verbeek in Stewart, 2008). The research project takes a designerly and participatory approach supported by action research methods for the development of a curriculum led, human-centred design protocol. This protocol aims to facilitate stakeholder engagement through to better understand the evolving nature and interrelationships of and between space, technology, pedagogy, curriculum and learning as complex open systems or human activity systems (Johnson \& Lamas, 2005; Loi \& Dillon, 2006). The following expands on the key theories and methods that inform the approach and methodology for this project.

\section{Methodology}

Next generation learning environments are complex design problems encompassing curriculum objectives, pedagogical approaches, stakeholder expectations, infrastructure and technology appropriateness, alongside the consultation, implementation and evaluation processes (Fisher, 2005). As such, next generation learning environments represent what design theory has referred to as 'wicked' or 'ill conceived' problems (Rittel \& Webber, 1973, Cross, 1982) and what soft systems theory terms as 'messy' problems (Checkland, 1981). 
Three key characteristics of 'wicked' problems that are also applicable to 'messy' problems are important to note here;

- There is no definitive formulation of the problem (Rittel \& Webber, 1973, Checkland, 1981)

- These types of problems are open ended and have no stopping rule (ibid)

- The planner has no right to be wrong (ibid).

In order to address the complexity and open-ended nature of next generation leaming environments the project uses an action research framework. This framework is guided by what Archer has termed a designerly approach to research (Archer, 1991) and incorporates three interrelated action research methods. Each of these methods aims to gain insights through cycles of critical reflection and action by researchers and participant stakeholders in the field.

\section{The Designerly Approach}

According to Archer, a designerly research approach is a way of moving from the general to the particular through iterative cycles of enquiry, experimentation or testing to develop an improved outcome. 'This approach starts with a broad configuration or 'rich picture' of what is required, then moves on to developing subsystems, then the details of these subsystems, through an iterative process which tests assumptions at the various stages (Archer, 1991). The outcome is one of a proposition for change and improvement. Three action research methods that are interrelated and complementary were identifed to support the designerly approach.

\section{Soft Systems}

Soft systems methodology provides an appropriate approach for mapping out the 'problem situation' at a Meta level; it assists in framing the 'problem situation', its boundaries, elements and interdependencies. As soft systems mapping of complex relationships is open ended, it allows for the ongoing evolution of the different elements with in the system. This methodology provides the broad 'system' configuration for the project and identifies the subsystems and relationships within it. Soft systems methodology was developed by Peter Checkland, emerging in the 1960's as an extension of biosystems methodology and hard systems methodology, as a way of applying systems thinking to non-systems situations such as those which incorporate high levels of social, political and human activity (Checkland, 1981, 2006). As in afl action research methods this methodology attempts to foster a learning community where the whole stakeholder group is involved in mapping out the "problem situation' allowing them to appreciate and contribute to an understanding of the situation and through this process identify desirable change, needs and actions leading to improvement in the 'problem situation'.

As in all systems methodology, a broad view is taken of what constitutes the system, what influences the system, who participates in the system and the relationships between these. This methodology was adopted by business in the 1980's (Senge, 1990) and more recently by design (Cotman \& Leadbetter, 2004) as a mechanism for defining the problem situation 
and analysing it leading to change, innovation and transformation. This methodology overlaps with the field of human-centred designing in terms of its participatory nature, its relational analysis and its focus on human activity.

\section{Human-centred Design}

Human-centred design supports and reinforces the human focus of a soft systems methodology. It provides insight into the dynamics of human practices and experiences in relation to designed environments and calls for participatory stakeholder engagements.

Human-centred designing has been gaining impetus since the 1990's. In that decade earlier user-centred approaches, that incorporate research data about potential users into the design process, were expanded and invigorated through engagement with participatory design techniques developed in Northern Europe (Sanders \& Stappers, 2008). These techniques engaged with potential users at all stages of the design process. Rather than seeing user representatives as passive sources of information, participants were actively included in the generative and evaluative process (Sanders, 1992). Respected voices within the field of design research who have contributed to the discussion on human-centred designing include Victor Margolin (1997), Donald Norman $(1996,2004)$ and Klaus Krippendorff $(2006)$. The resulting field encompasses diverse approaches to gaining insight into the relations between humans and designed things and environments. These approaches range from those that employ empirical or ethnographic research techniques, to more playful, innovative and designerly approaches, such as those developed by Bill Gaver (1999), or by Anthony Dunne and Fiona Raby (2002). Elizabeth Sanders, a leading proponent of human-centred designing, has provided a useful mapping of these approaches and the field (2006).

\section{Curricula-led}

Curricula can be described as systems that include students' and teachers' experiences of content, how content is structured and represented, teaching and learning practices, assess ment, evaluation and student support, situated within broader administrative, educational, practice and social contexts (Hicks, 2007). The aim here is to encapsulate what has been called design-based research in the Learning Sciences (Reeves, 2006). Design-based research involves using design experiments for formative research through iterative cycles of testing, evaluation, refinement and reflection in collaborative settings (Brown 1992, Collins 1992, Reeves 2006) and complements the other methodologies for the project. The process brings forth the curriculum objectives and the pedagogical approaches, leaming activities and technologies that will best support them. By placing design-based research within a systems perspective, a broader conception of curricula emerges. Within this broader conception learning environments can be seen as both places where the activities of the curriculum take place, and as part of the curriculum in themselves, in that students' perceptions of these enviroments create messages and experiences; messages about what the university sees as valued and important for learning, how learning might take place, the activities that support learning and the overall engagement with and experience of learning.

The above research methods engage with broad conceptions of curriculum, stakeholders and learning environments and through the action research process support the development of co-design partnerships across the stakeholder groups through participatory design. These 
partnerships are essential in order to develop trust, ownership and holistic understandings of the learning environment. Therefore the methodologies adopted recognize the breadth and the complexity of the project and enable transformative processes for curriculum, pedagogy and space across diverse stakeholder groups. They do this through facilitating collab. orative engagement, open communication, and learning through the related and complementary action research methodologies adopted for the project. Visual action methods introduce images, such as photos, symbols, diagrams and drawings in the action research process, encompassing, for example, research methods such as photo-elicitation, photo-voice, photo journals and concept or relational mapping (Corti, 1993, Hurworth, 2003). Visual action research, like all action research, involves collaborative processes, but here communication is fostered through a visual stimulus.

Collaboration, learning and communication are essential for positive change, particularly in complex contexts that represent socio-political systems with inherent conflict, power struggles and diverse stakeholder perspectives (Petheram, 2008); such as the higher education context. Learning, collaboration and communication are supported through the introduction of images to the action research method as they create a familiar and common language The method achieves validity through a cyclical procedure of critique, challenge, reassessment and refinement in dialectic of multiple information sources and perspectives (Dick \& Swepson, 1994). As in all action research, for the method to be reliable the development and testing of the protocol, tools and models was conceived of as an iterative, stakeholder inclusive, human-centred process which embeds evaluation and dissemination as an integral and ongoing process and provides an environment within which transformation and understanding can be pursued at the same time (Dick and Swepson, 1994).

\section{Protocols, Tools and Models}

Ideal spaces for new and emerging educational practice are human-centred, and inclusive of the views of the different stakeholders. As the spaces are conceived differently to traditional learning environments, they will be used differently, and will require different management strategies. The inclusion of teachers, students and facilities managers in the design process will enrich designers' understanding, and foster shared commitment by all stakeholders to the learning practices and curriculum goals that the spaces are intended to support.

Stakeholder engagement and consultation is seen as both an information elicitation process and a transformative process in the context of this project. The stakeholders involved in learning enviromments represent a diverse and stratified group with differing foci and project priorities that may remain firm or may shift during the course of a project. It was therefore necessary to develop processes, tools and models that allow for a cross-section of views and priorities to be brought forward, understood and discussed. For this discussion to be useful to design brief development, stakeholders need to feel some ownership of the project and have confidence that they are able to contribute freely and openly.

The project has involved participation from a broad cross-section of stakeholders including the university senior executive, students, academics, deans, associate deans (teaching and learning, and research), facilities management, faculty managers, designers and architects, to provide a cohort representative of a 'real project' for useful and meaningful feedback and evaluation. Putting the processes and tools into action is followed by objective evaluation, feedback and further development. The content of the workshops, focus groups, interviews, 
and journals are framed around a series of questions, probes or a scenario that relate to curriculum, graduate attributes, leaning space and technology. These frameworks wi l be further developed into models to become component parts of the protocol.

The following is an overview of the processes and tools being developed through the project for the purposes of stakeholder consultation to develop insights and understandings that can inform design brief development.

\section{Visual Cue Cards}

A visual cue card tool was designed in response to an unexpected difficulty discovered in the first project team workshop: a simple reluctance amongst participants (other than designers) to draw pictures, an activity that is central to the development of 'rich pictures' in soft systems methodology. Using visual images in lieu of drawing seemed a possible alternative to commence the process of investigation. Drawing on research on photo elicitation the concept of using visual images in lieu of drawings was seen as an appropriate addition to the action research framework. In research or enquiry situations, images whether photographic or abstract representations, evoke deeper responses and often represent 'a different kind of information' than is brought forward through words alone (Harper, 2002: 13), information that can be particularly insightful. Photo elicitation, as the term suggests, uses photos however the principles apply to virtually all forms of visual images (Harper, 2002).

A series of visual action tools were developed to overcome participants" reluctance to draw, and shift the emphasis from dialogue to visual narrative, to eliminate personal agendas and power plays, and provide for a more collaborative model of stakeholder consultation. The development and testing of the first tool, visual cue cards, has taken on two primary models, one through a workshop model of enquiry and the other through a focus group model of enquiry.

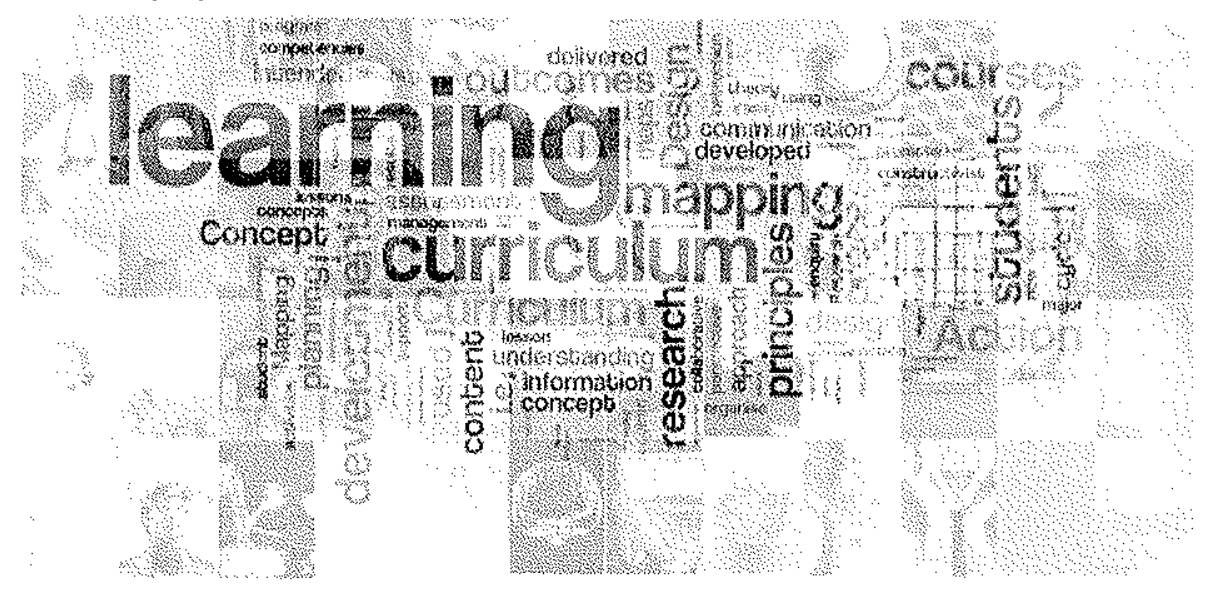

The visual cue card tool involves a series of visual cue card decks that are being developed through iterative cycles of testing, evaluation and refinement. The cue cards stipport visual action research and relate to photo elicitation (Corti, 1993, Banks, 1995, 2001) and game play (Carse, 1986, Brandt, 2008) providing mechanisms for collaborative engagement in 
creating past, present and future worlds or 'what if?' situations in which participants (players) have equal voice, and socio-political stratification is minimized.

The visual cue cards are used in an action research framework and draw on game and play theory to engage participants and facilitate safe or politically neutral environments that allow participants to develop shared conceptual understandings through visual representations, narrative and co-creation. The cue cards can be used in a variety of scenarios in both participatory and collaborative ways, either in onemon-one interviews, workshops, and focus groups, or as expressions in photo journals.

\section{Workshop Envisioning}

In the context of this project 'a workshop refers to interactive, usually one-off, intensive, face-to-face, educational initiatives that require input from all present and result in benefits for both participants and facilitator's' (ALTC Working with Workshops). The workshops are conceived of as both transformative processes, and data/information elicitation, gathering and analysis. Workshops are designed to address different aspects at different stages of the project ranging from curriculam design, pedagogy \& technology to leanning space design.

The workshop model of stakeholder engagement is seen as an effective means of capturing and sharing a diverse range of views, expertise, and knowledge and a mode for eliciting information in nonthreatening ways. Through the introduction of the cue card tool participants in the workshops negotiate shared understandings through a visual narrative. The visual language of the cue cards is familiar and immediately brings forth feelings, memories and perspectives that are difficult to unlock through traditional dialogue (Harper, 2002).

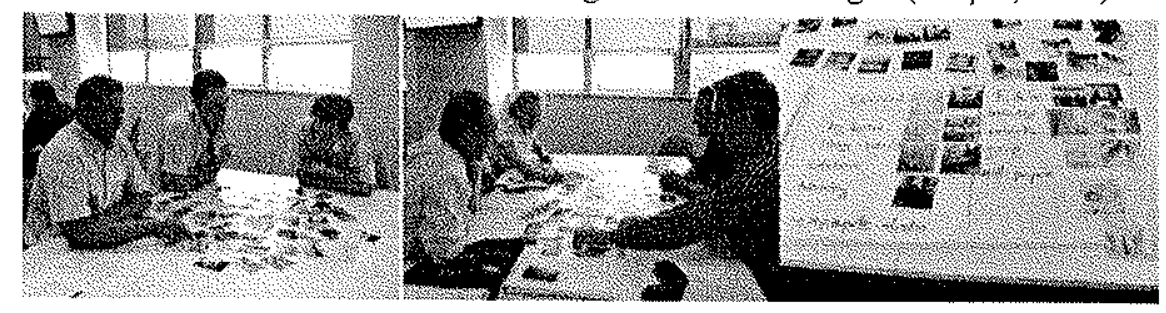

Action research workshops can take many forms to address specific intentions. The following are three examples that are useful within the context of the project:

Execulive Strategic Envisioning - Used to capture culture, values, strategic directions, objectives, ownership, authorship, motivations and aspirations of a group and generally involve key decision makers.

Past Present Future - Transformative process to assist in identifying change that has happened, is currently happening and that still needs to happen. These workshops often bring forth new insights for participants in tems of the perspectives of others but also the scope and rate of change already in action.

Appreciative Enquiry - is a process or positive search that looks for what is currently valued or appreciated, what is working well and why, in order to understand or uncover what supports 'success' in a given scenario and how this may be extended or improved. This model is particularly relevant for situations prone to conflict and defensive behaviour: 
As a participatory method, workshops, like focus groups promote interaction, negotiated understandings and new insights that draw on participants' attitudes, feelings, belief's and knowledge of the situation in question (Gibbs, 1997). Workshops, like focus groups, also play on group behaviour, that is, participants seek to develop norms and shared goals or understandings (Lawson, 2005).

\section{Focus Groups}

Widely used in market research, focus groups are not as common in social science or design research generally (Gibbs 1997). The benefit of focus groups is the interaction within the group and the opportunities for the eliciting of multiple or shared views within a group context and the reevaluation of individual views in light of discussion. Focus groups draw upon the attitudes, feelings, beliefs, experiences and reactions of participants and allow researchers to uncover what is salient and why (Gibbs, 1997, Morgan, 1988).

Focus groups can either be empowering, with the group working as a unit and trust developing, or they can be intimidating for individuals. The introduction of visual cue cards provides a starting point to prompt or stimulate dialogue and elicit information. Individuals are united through a common non-threatening and familiar stimulus. As with workshops, what is important in focus groups are the insights and information or data brought forth through the interaction of the participants (Gibbs, 1997)

Focus groups can be used in the preliminary and exploratory stages of a project and also the evaluation stages of a project. In combination with other methods they provide for triangulation and validity testing (Morgan, 1998, Gibbs, 1997).

\section{Photo Interviews}

The use of visual prompts in interviews is not a new method. It has been widely used in anthropology and the social sciences more generally. Interest in this technique has received renewed attention over the past decade (Hurworth, 2003).

Using images as prompts in the interview situation has several benefits as images are readily identifiable and interviewees tend to respond to photos 'without hesitation'; the familiarity of viewing photos assists in averting the strangeness of the interview construct (Shwartz, 1989). Photos can also act to trigger and enhance memory, represent abstract and difficult concepts, develop commenity perspectives and enable comparable responses amongst diverse groups (Hurworth, 2003)

Photo interviews can either be driven by images selected by the researcher for the interviewee to comment upon or they can be 'autodriven' by photographs authored by the interviewees to capture their own behaviours and environments. The later form gives the interviewee increased voice and is particularly useful in gaining negotiated understanding of events and relational dynamics (Heisley \& Levy, 1991). This technique is similar to reflexive photography where the interviewee takes photos and then reflects on these in the interview.

\section{'Day in the life' Photo Journals}

This process uses two to three methods in combination. 


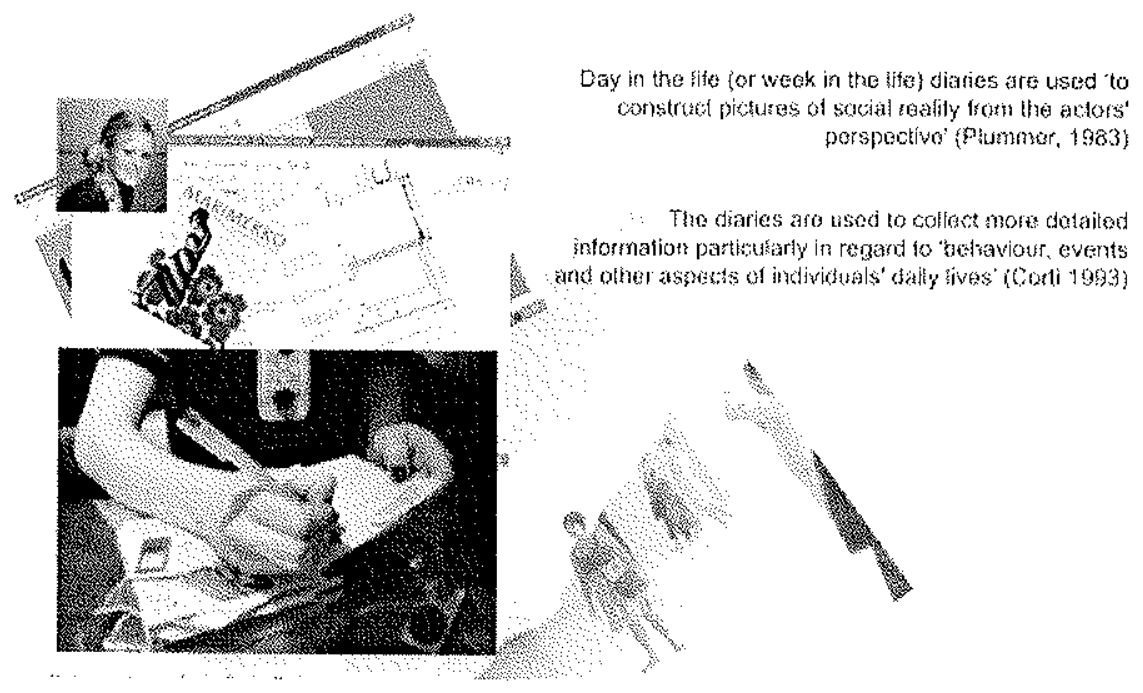

Photo voice methodology, is a form of participatory action research, developed by Wang and Burris, which 'engages the participant as a photographer who captures photos that best illustrate his or her perspective' (Barrett, 2001). A question or series of questions are posed to the participants and they are asked to capture images of what best addresses these questions. Qualifying statements accompany the photos to provide deeper insights. In the same way as 'autodriven' photo interviews increase stakeholder voice, the photo joumal represents 'life as they see it' (Hurworth, 2003).

Day in the life (or week in the life) diaries are used 'to construct pictures of social reality from the actors' perspective', in this case the students' (Plummer, 1983, Corti, 1993). The diaries are used to collect more detailed information particularly in regard to 'behaviour, events and other aspects of individuals' daily lives' (Corti, 1993).

Self-completion research instruments such as joumals and diaries have a number of advantages over other data collection research instruments. They are extremely reliable as they provide instant recall of events, responses, activities and feelings and can be conducted in anonymous ways to overcome sensitivity about personal information and opinions (Corti, 1993). As a source of information they can supplement interviews and/or focus groups, or become the subject of interviews and focus groups, to elicit more detailed and rich information and insights.

The journals and diaries take on a structured format rather than a free format to allow for easier analysis of the data. Some open or free sections are included in the journals and diaries to allow for greater opportunity for understanding the stakeholders' needs and perceptions.

The aim of the joumals and diaries is to record and reflect on what the participants see as assets and concerns. This is a method often used to engage students in the consultation process and allow them to highlight issues of importance that are then critically discussed in focus groups and workshops, and can be used to communicate the issues to policy and decision makers. 
DESIGN PRINCIPLES AND PRACTICES: AN INTERNATIONAL JOURNAL

\section{Curriculum Mapping}

The project team is currently developing tools and a model for curriculum mapping that draws on the three methodologies previously discussed and which will involve visual action research methods. These include the use of the visual cue cards, persona development and concept mapping. The use of these tools and methods aims to promote fiuid discussion and development of rich pictures relating to curriculum objectives, learning stances or preferences, learning activities, space and technology in propositional and relational ways.

The above methods of stakeholder engagement will be developed into models and along with the tools form part of the tool kit and protocol for the development of design briefs for curriculum-led, human-centred learning environments and the assessment of their success. The protocol being developed embraces human-centred participatory design, it is therefore fitting for the methods being developed to encompass similar principles and values.

\section{Conclusion}

The conception and design of next generation leaming environments is a complex process that involves multi-level and diverse stakeholder groups. Through the use of action research methods, in particular visual action research methods, 'rich pictures' can be developed and understandings gained across stakeholder groups through their participation and contribution to the project at all stages, from inception and initiation to occupation and evaluation. Through the use of visual action methods, hierarchies and barriers are broken down and stakeholders can engage in participatory processes that elicit insights, shared understandings and support transformational processes.

Through a designerly approach (Archer, 1991) this project embraces a broad cross-section of action research methodologies with a particular focus on visual action research methods. The methods adopted support a human-centred and participatory approach that is propositional in its nature and promises to elicit 'designerly ways of knowing' (Cross, 1982). Through the generation of shared understandings these methods act as vehicles for promoting and facilitating positive change. Whilst this project is still in process, work to date has evidenced the appropriateness of visual action research methods to the design process as methods for scaffolding participatory processes.

\section{References}

Archer, 13., 1991, The Nature of Research into Design and Design Education, Keynote Address IDATER, Department of Design and Technology, loughborough University, pp. $18-26$

Banks, M., 1995, 'Visual research methods', Social Issues Update, Issue 11, Winter, Department of Sociology, University of Surrey, Guildford

Banks, M., 2001, hisual methods in social research, Sage, London

Barret, 1.1, \& Young, L., 2001, Adapting Visual Methods: Action research with Kampala Street Children ISTOR: Area, Vol. 33, No. 2, pp. [41-]52

Brand, E., Messeter, J., \& Binder, T., 2008, 'lomatting design dialogues - games and participation', CoDesign, Vol. 4, No. 1, pp.5!-64

Brown, A. L., 1992, 'Design experiments: Theoretical and methodological challenges in creating complex interventions in classroom settings', The Joumal of the Leaming Sciences, Vol. 2, No.2, pp. 141-178.

Carse, J.P., 1986, Finite \& Infinite Games: A Vision of Life in Play and Possibility, Free Press. NY 
Collins, A., 1992, "Towards a design science of education', New directions in educational technology, Eds. E. Scanlon \& 'T. O'Slyea, pp. 15 22, Springer, Berlin

Checkland, P., (1981), Systems Thinking, Systems Practice, Wiley, New York

Checkland, P. \& Poulter, 1., (2006), Learning for action: a short definitive acoont of soft systems methodology and its use for practitone; teachers, and students, John Wiley \& Sons, Hoboken

Corti, L., 1993, 'Using diaries in social research', Social Issues Update, Issue 2, Department of Soci ology, University of Surcy, Guildford

Cotman \& Leadbetter, 2004, Red Paper - Healh: Co-creating Services, UK Design Council

Cross, N., 1982, 'Designerly ways of knowing', Design Studies, Vol.3, No.4, pp.221-227

Dick, B. \& Swepson, P., 1994, Appropriate validity and its attainment within action research: an illustration using solt systems methodology [On line]. htup://www.scu.edu,au/schools/gem/ar/arp/solsys2.htm]

Dume, A., and Raby, F., (2002), The Placebo Project, proceedings of the th conrerence on Designing Interactive Systems: processes, practices, methods and techniques, London lingland

Fisher, K., (2005), Linking pedagogy and Space, Department of Education and Training, Victoria, \& (2007), Aligning space, place and leaning modalities, Carrick Places and Spaces for learning Seminar Series

Gaver, B., Dumne, A., \& Acenti, I., 1999, 'Cultural Probes', Interactions,

Gee, L., 2006, 'Human-Centered Design Guidelines, Learning Spaces', Chapter 10, Educause

Gibbs, A., 1997, 'T'ocus Groups', Social lssues Update, Issue 19, Winter, Department of Sociology, University of Surrey, Guildford

Haper, D. 2002, "Taking about pictures: a case for photo elicitation", V/stal Studies, Vol. 17, No.1 pp. 13-26, Routledge

Heisley, DD \& Levy, SI 1991, 'Autodriving: a photoclicitation technique', Journal of Consumer Research, vol, 18 , pp. $257-72$.

Hicks, O., 2007, 'Curriculum in Higher Education-Hello', Enhancing Higher Education, Theory and Scholarship, Proceedings of the 30th HERDSA Annual Conference

IHurworth, R., 2003, 'Photo-Interviewing for research', Social lssues Update, Issue 40, Spring, Department of Sociology, University of Surrey, Guildford

Jamieson, P., (2007), The Carrick Institute forum on the Design of Learning linvironments

Johnson, C. \& Lamas, C., 2005, Design of the Leaning Space: Leaning and Design Principles, Educause Review, Vol.40, No. 4, pp. 16-28

Krippendorf, K., (2006), The semantic num: a new foundation for design, Taylor and Trancis, Boca Raton, London \& New York.

Lawson, B., 2005, How Designers Think: the design process demystified, $4^{\text {th }}$ ed. Amsterdam: The Architectural Press, Elsevier

Loi, D \& Dillon, P., (2006), Adaptive Educational Environments as Creative Spaces, Cambridge Journal ol Education 36(3), Oxford, UK: Routledge

Margolin, A., Getting to know the user, Design Sudies Vol.18, No.3, pp.227-236

Morgan D.L. 1998, Focus groups as qualitative research, 2nd Bdition, Sage, London

Norman, D., 2004, Emotional Design, Basic Books, New York

Petheram, L., 2008, Visual techiques in facilitating learning and communication in environmental management. Charles Darwin University,

Plummer, K., 1983, Documents of Life, Allen \& Unwin, London.

Reeves, T. C., 2006, 'Design research from the technology perspective', Educational design research, Lds. J. V. Akker, K. Gravemejjer, S. McKenney, \& N. Nieveen, pp. 86-109, Routledge, London

Rittel, H., and Webber: M., (1973), Dilemmas in a General Theory of Planning, Policy Sciences, Vol. 4, pp. 155-169, Elsevier Scientific Publishing Company, Inc., Amsterdam, [Reprinted in N. Cross (ed.), Developments in Design Methodology, J. Wiley \& Sons, Chichester, 1984, pp. [35- 144.] 


\section{DESIGN PRINCIPLES AND PRACTICES: AN INTERNATIONAL JOURNAL}

Sanders, E. (1992) "Converging perspectives: Product development research for the 1990s" Design Managemen Journal, Vol.3, No.4.

Sanders, E. and Stappers, P., 2008, "Co-creation and the new landscapes of design", CoDesign, Vol.4, No.1, pp.5.18

Sanders, E., 2006, Design Research in 2006, Design Research Quarterty, Vol.1. No.7, pp.1-8

Senge, P. 1990, The Fifh Discipline, Doubleday, NY \& Random House, Sydney

Schwartz, D. (1989) Visual Ethography: Using Photography in Quafitative Research. Qualitative Sociology, 12, 2, 119-154.

Stewart, S., (2008), Interior Design activity from a Design Studies perspective, in The Future of Design: a 2020 Vision --internal faculty report, Sherringham, S.

\section{About the Author}

Susan Sherringham

Susan Sherringham ( BA (Hons)), is Course Director of Interior Design in the Faculty of Design Architecture and Building, the University of Technology Sydney (UTS). She is Chair of the Teaching and Learning Spaces Improvement Working Party at UTS. Susan has over 20 years of industry experience as a designer, as a Director of a multidisciplinary design practice and in her own multidisciplinary design practice, primarily designing for the commercial sector including research and development projects. Her curent post graduate research focuses on adaptive expertise, systems thinking, organisational leaming and life-long leaning in the design industry; an aspect of which is conceptualising the workplace as a learning environment. Susan is Project Leader on an Australian Learning and teaching Council Priority Project - A protocol for developing curriculum-led human-centred learning enviromments in higher education. Susan is also a Director and Treasurer of the Interior Design/Interior Architecture Educators Association. 


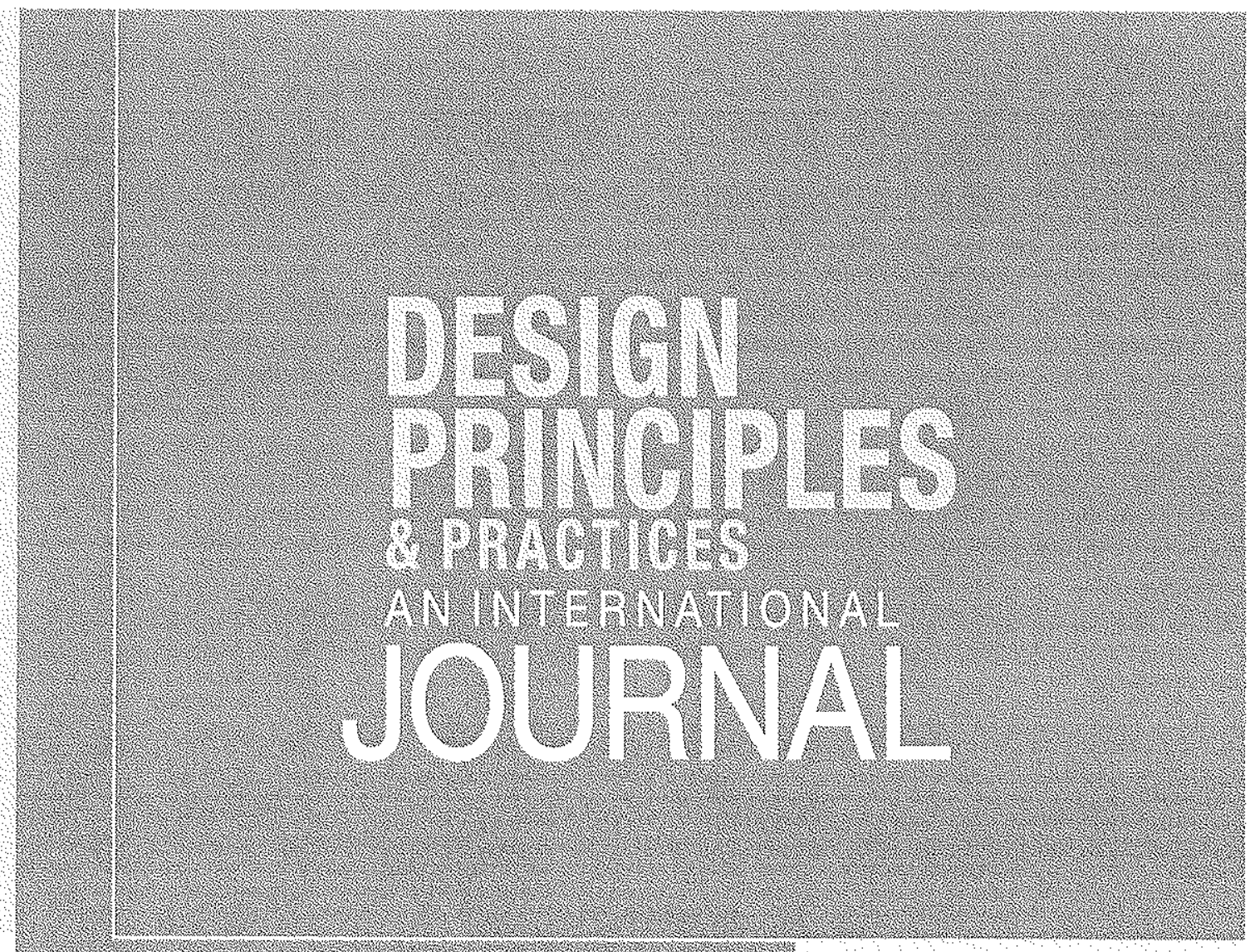

Volume 4, Number 3

Developing Curriculum-Led Human-Centred Spatial Design Briefs for Next Generation Learning Environments in Higher Education

Susan Sherringham (1) $\begin{array}{cccccc}C & O & M & M & 0 & N \\ G & R & 0 & \cup & N & D\end{array}$ 
DESIGN PRINCIPLES AND PRACTICES: AN INTERNATIONAL JOURNAL

http://www.Design-Journal.com

First published in 2010 in Champaign, Illinois, USA by Common Ground Publishing LLC www.CommonGroundPublishing.com.

(C) 2010 (individual papers), the author(s)

(C) 2010 (selection and editorial matter) Common Ground

Authors are responsible for the accuracy of citations, quotations, diagrams, tables and maps.

All rights reserved. Apart from fair use for the purposes of study, research, criticism or review as permitted under the Copyright Act (Australia), no part of this work may be reproduced without written permission from the publisher. For permissions and other inquiries, please contact

$<$ cg-support@commongroundpublishing.com>.

ISSN: 1833-1874

Publisher Site: http://www.Design-Journal.com

DESIGN PRINCIPLES AND PRACTICES: AN INTERNATIONAL JOURNAL is peerreviewed, supported by rigorous processes of criterion-referenced article ranking and qualitative commentary, ensuring that only intellectual work of the greatest substance and highest significance is published.

Typeset in Common Ground Markup Language using CGCreator multichannel typesetting system

http://www.commongroundpublishing.com/software/ 


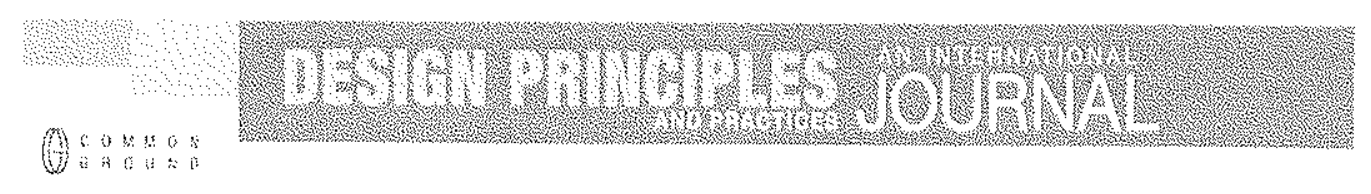

\section{EDITORS}

Bill Cope, University of Illinois, Urbana-Champaign, USA.

Mary Kalantzis, University of Illinois, Urbana-Champaign, USA.

\section{EDITORIAL ADVISORY BOARD}

Genevieve Bell - Intel Corporation, Santa Clara, USA.

Michael Biggs - University of Hertfordshire, Hertfordshire, UK.

Thomas Binder - Royal Danish Academy of Fine Arts, Copenhagen, Denmark.

Jeanette Blomberg - IBM Almaden Research Center, San Jose, USA.

Eva Brandt - Danmark Designskole, Copenhagen, Denmark.

Peter Burrows - RMIT University, Melbourne, Australia.

Monika Büscher - Lancaster University, Lancaster, UK.

Bill Cope - University of Ilinois, Urbana-Champaign, USA

Patrick Dillon - Exeter University, Exeter, UK.

Kees Dorst - TUe, The Netherlands; UTS, Australia.

Michael Gibson, University of North Texas, Denton, USA.

Judith Gregory - IIT Institute of Design, Chicago, USA; University of Oslo, Oslo, Norway.

Clive Holtham - City of London University, London, UK.

Hiroshi Ishii - MIT Media Lab, Cambridge, USA.

Gianni Jacucci - University of Trento, Trento, Italy.

Mary Kalantzis - University of Illinois, Urbana-Champaign, USA.

Klaus Krippendorff - University of Pennsylvania, Philadelphia, USA.

Terence Love - Curtin University, Perth, Australia.

Bill Lucas, MAYA Fellow, MAYA Design, Inc., Pittsburgh, USA.

Ezio Manzini - Politecnico of Milano, Milan, Italy.

Mario Minichiello, Birmingham Institute of Art and Design, Birmingham, UK.

Julian Orr - Work Practice \& Technology Associates, Pescadero, USA.

Mahendra Patel - Leaf Design, Mumbai, India.

Toni Robertson - University of Technology Sydney, Sydney, Australia.

Terry Rosenberg - Goldsmiths, University of London, London, UK.

Keith Russell - Universizy of Newcastle, Callaghan, Australia.

Liz Sanders - Make Tools, USA.

Maria Cecilia Loschiavo dos Santos - University of São Paulo, São Paulo, Brazil.

Lucy Suchman - Lancaster University, Lancaster, UK.

Ina Wagner - Technical University of Vienna, Vienna, Austria.

Please visit the Journal website at http://www. Design-Journal.com for further information about the Journal or to subscribe. 